\title{
Malignant Transformation of Schneiderian Papilloma Presenting With Progressive Binocular Diplopia and Blepharoptosis
}

\author{
Oraianthi Fiste ${ }^{1}$, Anastasia Tsiogka ${ }^{2}$, Eleni Arvanitou ${ }^{3}$, Athanasios Karampeazis ${ }^{4}$, Charalampos
} Christofyllakis ${ }^{3}$

1. Department of Clinical Therapeutics, School of Medicine, National and Kapodistrian University of Athens, Athens, GRC 2. Department of Opthalmology, 401 General Military Hospital of Athens, Athens, GRC 3. Department of Oncology, 401 General Military Hospital of Athens, Athens, GRC 4. Department of Oncology, 401 Genaral Military Hospital of Athens, Athens, GRC

Corresponding author: Anastasia Tsiogka, anastasia.tsioga@gmail.com

\begin{abstract}
Sinonasal tumors arising from Schneiderian papillomas, most frequently associated with squamous cell carcinoma (SCC), are rare and often present with non-specific symptoms, even in an advanced stage. Herein, we report the case of a 61-year-old male who presented with a four-month history of progressive binocular diplopia, blepharoptosis, and amblyopia, and upon the essential diagnostic work-up he was subsequently diagnosed with SCC arising from an SP. Surgical management was not warranted due to the extent of the disease, so induction chemotherapy with cisplatin and 5-fluorouracil (5-FU) was commenced, followed by definitive concurrent chemoradiotherapy (CRT). The patient was still alive at 25 months after his first presentation, receiving supportive care. Our case highlights the importance of early recognition of neuroophthalmological disorders related to sinonasal carcinomas, as diagnostic delay may lead to both functional complications and higher morbidity.
\end{abstract}

Received 08/13/2020

Review began 09/01/2020 Review ended 09/13/2020 Published 09/17/2020

๑) Copyright 2020

Fiste et al. This is an open access article distributed under the terms of the Creative Commons Attribution License CC-BY 4.0., which permits unrestricted use, distribution, and reproduction in any medium, provided the original author and source are credited.
Categories: Neurology, Ophthalmology, Oncology

Keywords: schneiderian papilloma, malignant trasformation, diplopia, blepharoptosis, oncology, ophthalmology

\section{Introduction}

Schneiderian papillomas (SPs) are rare benign, sinonasal tumors [1]. Malignant transformation, albeit uncommon (0.04 cases per 100,000 population) [1], most frequently relates with squamous cell carcinoma (SCC) [2]. Occupational hazards including wood and leather dust have been characterized as causative factors of SP-derived SCCs, whereas, smoking and human papilloma virus (HPV) infection have been suggested to contribute to disease risk [3-5]. Considering their rarity and manifold clinical manifestation [1], early diagnosis poses challenges, whilst optimal management remains an unmet need. In this paper, we describe an additional case of SP-derived SCC presenting with ophthalmological symptoms [6] and critically discuss the published literature on the epidemiology, diagnosis, and treatment of this aggressive malignancy.

\section{Case Presentation}

A 61-year-old male was referred to the emergency department with progressive binocular diplopia, blepharoptosis, and amblyopia of four-month duration. He was a heavy smoker with a medical history of moderate alcohol consumption, post-traumatic mydriasis of the right eye, hypertension, and recent intranasal papilloma-plucking for which he underwent a polypectomy excision.

The best corrected distance visual acuity was "hand motion" in the right eye and 1/20 in the left eye (Snellen chart). Ocular motility was abnormal. He had complete ophthalmoplegia with exophthalmos and blepharoptosis in the right eye and sixth nerve palsy in the left eye. Visual fields were abnormal to confrontation visual field examination (Donders' test) with bilateral inferior altitudinal visual field defects.

Brain imaging techniques, including computed tomography (CT; Figure 1) and magnetic resonance imaging (MRI; Figure 2) both revealed an $11 \mathrm{~cm}$ sized mass from the height of the ethmoidal air cells to the ground of the oropharynx, which erodes the maxillary-, the frontal-, the ethmoid-, the sphenoid-bones, and the clivus. Histology on the surgical specimen of the resected nasal polyp, acquired by an ear, nose and throat (ENT) specialist, confirmed the presence of SCC arising from an SP (Figure 3). 


\section{Cureus}

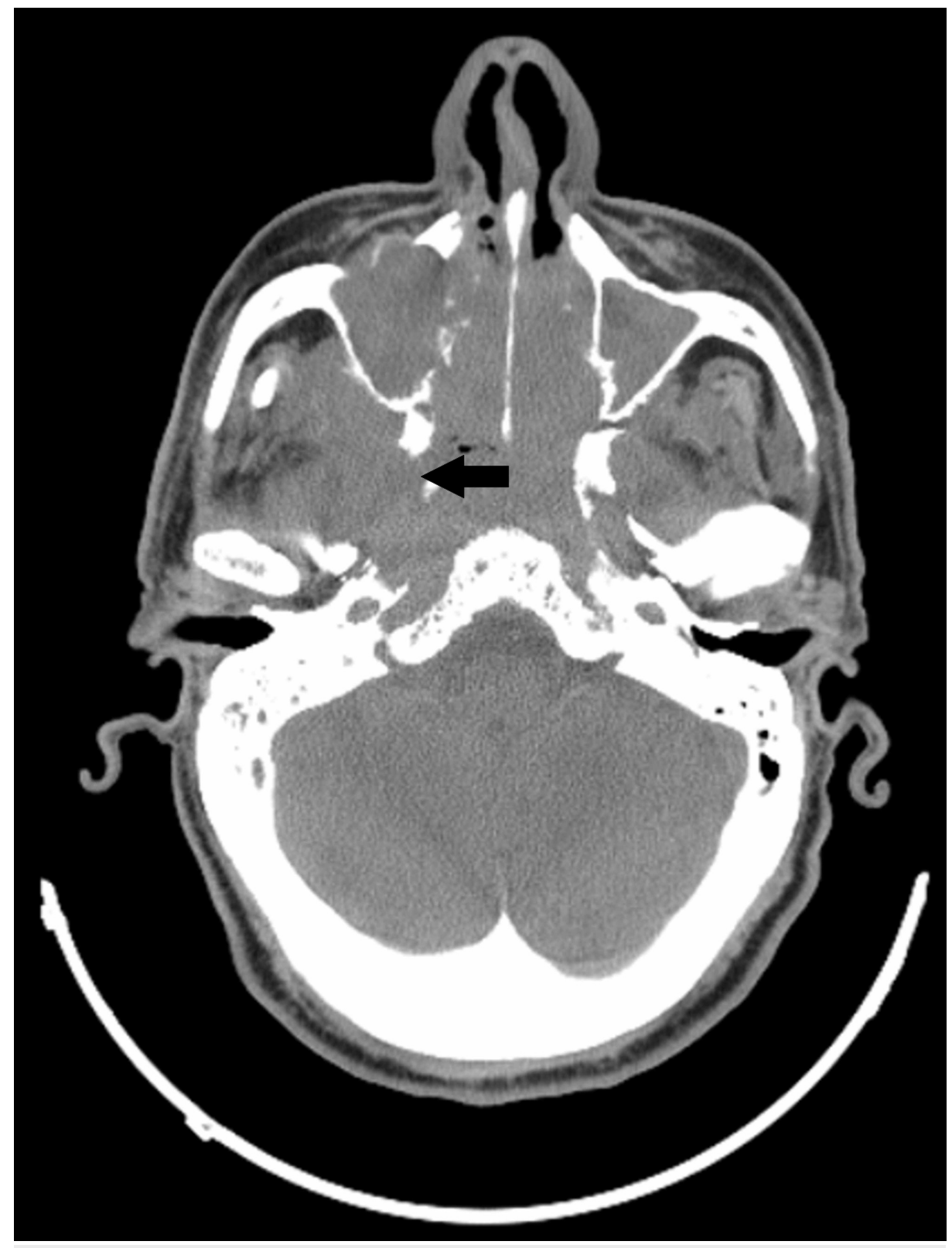

FIGURE 1: CT scan depicting the tumor (black arrow) from the height of the ethmoidal air cells to the ground of the oropharynx eroding different bones of the area. 


\section{Cureus}

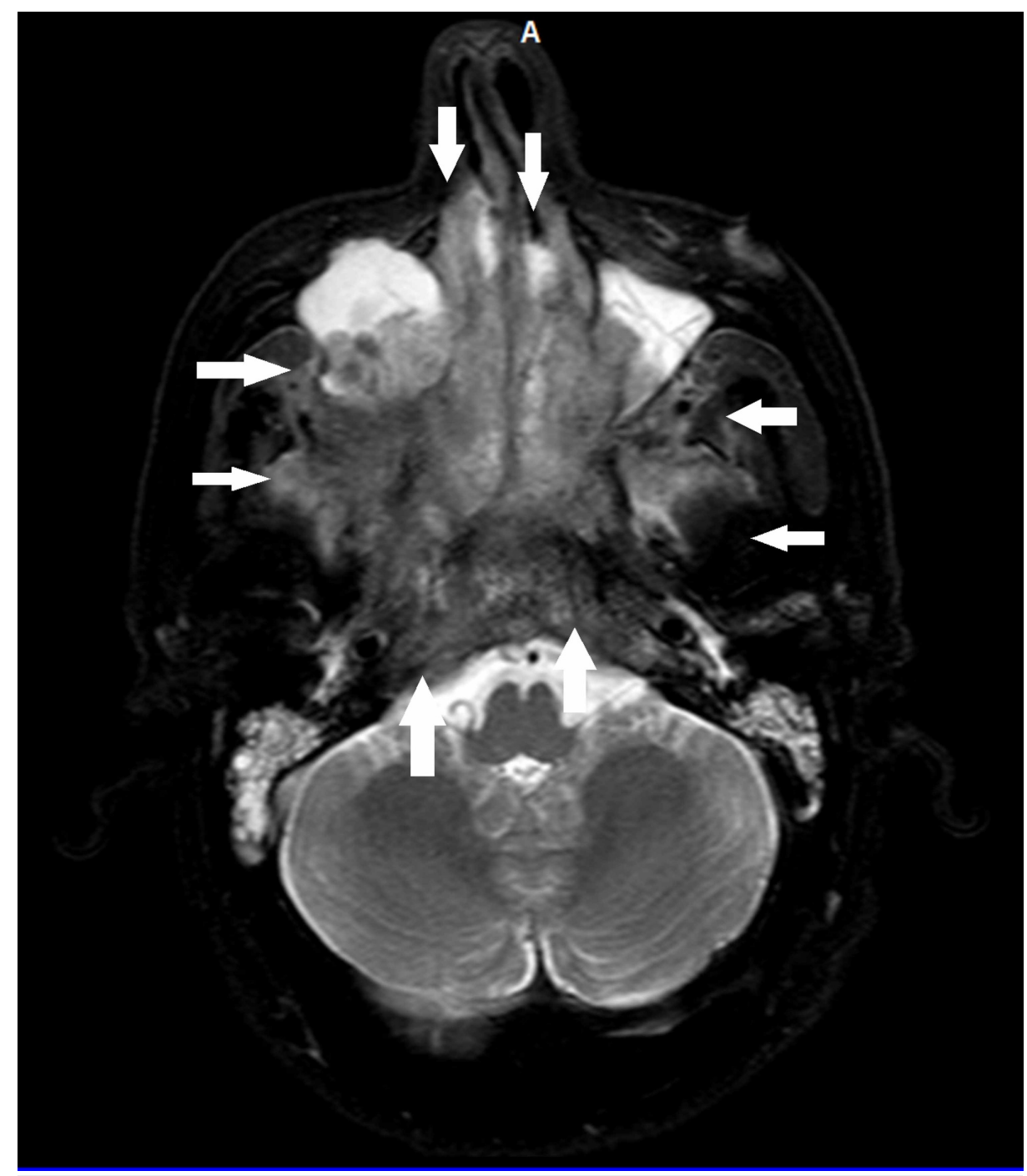

FIGURE 2: MRI scan depicting the size of the tumor extension (white arrows).

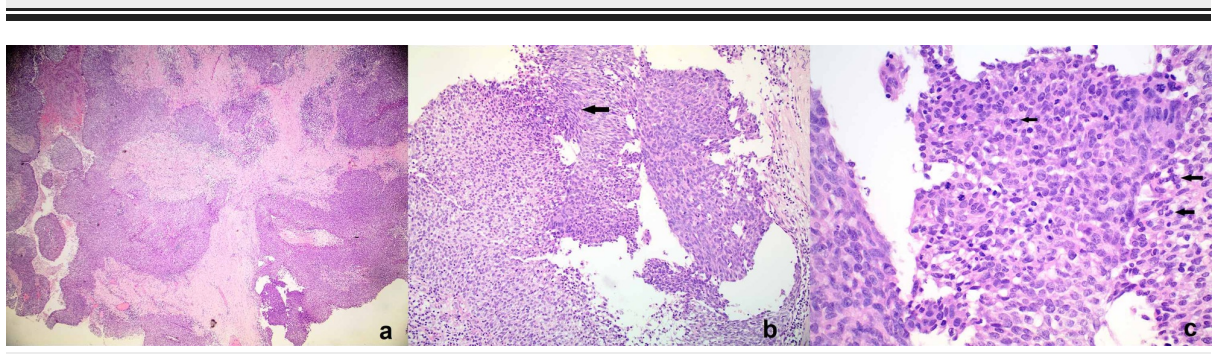

\section{FIGURE 3: Histopathological examination of the "nasal polyp."}

(a) Low view of sinosal (Schneiderian) papilloma, inverted and exophytic type, with malignant transformation. (b) Area of transition from the benign epithelium into the area of the malignant epithelium (black arrow). There is increased cellularity, pleomorphism, disorganization, and an increased number of mitoses. (c) High magnification shows the remarkable increased number of mitoses, including atypical forms (black arrows).

Due to the extension of the disease, surgical excision was not feasible; thus, the patient received three cycles of induction chemotherapy with the cisplatin plus 5 -fluorouracil (5-FU) combination, followed by radical concurrent chemoradiotherapy (CRT) (63.6 Gy in 30 fractions with weekly cisplatin) with manageable toxicity, partial imaging response, and clinical improvement. The patient was alive 25 months postdiagnosis with progressive disease, receiving the best supportive care. 


\section{Discussion}

Schneiderian papillomas (SPs), arising from the ectodermally derived respiratory mucosa, account for 0.5$4.0 \%$ of all sinonasal tract tumors $[1,5]$. They are represented by three morphologically distinct types of papillomas; inverted (ISP), oncocytic (OSP), and exophytic (ESP) sinonasal papilloma, and are classified as benign neoplasms [1]. Malignant transformation of SPs, either synchronous or metachronous, is identified in less than $9 \%$ of reported cases, most frequently to SCC [1].

The precise nature of this oncogenic transformation has not been clearly defined; thus, there is an unmet need for further studies into pathogenetic factors of SP-derived SCCs, including the ambiguous role of human papilloma virus type 16 (HPV-16) infection [5,7-9]. Moreover, further evidence is warranted to support tobacco smoking as an etiological factor, despite it relates with increased risk of sinonasal SCCs and is a well-established, modifiable risk factor for head and neck cancer [10]. Also, occupational exposure to wood, leather dust, formaldehyde, nickel, and glues has been strongly associated with tumorigenesis of sinonasal SCCs $[3,4,11]$.

The vast majority of the patients are in general middle-aged males, who present with long symptom duration and advanced-stage disease $[1,11,12]$. Clinical manifestations of SPs and SP-derived SCCs include unilateral nasal obstruction, epistaxis, headache, sinusitis, anosmia, otitis, vertigo or hearing loss, and ophthalmologic symptoms like diplopia and periorbital swelling [1].

Treatment guidelines for SP-derived SCCs have not yet been established due to their rarity; yet, a multimodality approach including surgery, radiotherapy (RT), and chemotherapy are most commonly employed. Definitive tumor resection, by open craniofacial or endoscopic-assisted approaches, followed by adjuvant RT, results in superior oncologic outcomes compared with CRT, or RT alone, and is considered the optimal treatment of sinonasal SCCs [13-15]. However, in daily clinical practice, the indicated therapeutic modality depends not only on the exact site and extent of the disease but also on the availability of surgical technologies and experience [13]. Nevertheless, the prognosis of SP-derived SCCs remains poor, with an overall five-year survival rate of 30-50\% [14]. In the future, the introduction of (a) less invasive and more precise robot-assisted surgery [16], (b) sophisticated RT techniques like intensity-modulated radiation therapy (IMRT), volumetric modulated arc therapy (VMAT), and proton-beam therapy [17-19], and (c) targeted therapies like cetuximab for tumors overexpressing epidermal growth factor receptor [20] might reduce toxicity and increase therapeutic efficiency, thus contribute to significant improvements in both quality of life and survival outcomes.

\section{Conclusions}

SCCs derived from benign SPs are exceedingly rare sinonasal tumors, known to carry a dismal prognosis. Their distinctive characteristics differentiate them from the rest of head and neck cancers, while their clinical presentation includes a broad spectrum of non-specific, atypical symptoms. Diagnosis remains challenging, whereas the complex anatomy of the sinonasal cavity poses therapeutic challenges. Developments in endoscopic surgery, RT, and molecular targeted therapies lay the foundations for optimal management in the near future.

\section{Additional Information \\ Disclosures}

Human subjects: Consent was obtained by all participants in this study. Conflicts of interest: In compliance with the ICMJE uniform disclosure form, all authors declare the following: Payment/services info: All authors have declared that no financial support was received from any organization for the submitted work. Financial relationships: All authors have declared that they have no financial relationships at present or within the previous three years with any organizations that might have an interest in the submitted work. Other relationships: All authors have declared that there are no other relationships or activities that could appear to have influenced the submitted work.

\section{Acknowledgements}

We would like to thank Dr Kiriakos Grigoriadis, from “GK Pathology” Pathologoanatomic Center of Athens, for diagnosing Schneiderian papilloma. We would also like to thank Dr Georgia Papadopoulou, from Pathologoanatomic Department of 401 General Military Hospital of Athens, for providing us with pictures of the carcinoma ex-Schneiderian papilloma.

\section{References}

1. Nudell J, Chiosea S, Thompson LD: Carcinoma ex-Schneiderian papilloma (malignant transformation): a clinicopathologic and immunophenotypic study of 20 cases combined with a comprehensive review of the literature. Head Neck Pathol. 2014, 8:269-286. 10.1007/s12105-014-0527-7

2. Jeong HJ, Roh J, Lee BJ, Cho KJ: Low-grade papillary Schneiderian carcinoma: a case report . Head Neck Pathol. 2018, 12:131-135. 10.1007/s12105-017-0832-z 
3. Cantu G, Solero CL, Mariani L, et al.: Intestinal type adenocarcinoma of the ethmoid sinus in wood and leather workers: a retrospective study of 153 cases. Head Neck. 2011, 33:535-542. 10.1002/hed.21485

4. IARC Working Group on the Evaluation of Carcinogenic Risks to Humans: Arsenic, metals, fibres, and dusts . IARC Monogr Eval Carcinog Risks Hum. 2012, 100:11-465.

5. Strojan P, Ferlito A, Lund VJ, Kennedy DW, Silver CE, Rinaldo A, Barnes L: Sinonasal inverted papilloma associated with malignancy: the role of human papillomavirus infection and its implications for radiotherapy. Oral Oncol. 2012, 48:216-218. 10.1016/j.oraloncology.2011.10.009

6. Fiste O, Karampeazis A, Karamaounas N, et al.: 25th Hellenic conference of clinical oncology . Forum Clin Oncol. 2019, 10:1-62. 10.2478/fco-2019-0001

7. Weindorf SC, Brown NA, McHugh JB, Udager AM: Sinonasal papillomas and carcinomas: a contemporary update with review of an emerging molecular classification. Arch Pathol Lab Med. 2019, 143:1304-1316. 10.5858/arpa.2019-0372-RA

8. Sahnane N, Ottini G, Turri-Zanoni M, et al.: Comprehensive analysis of HPV infection, EGFR exon 20 mutations and LINE1 hypomethylation as risk factors for malignant transformation of sinonasal-inverted papilloma to squamous cell carcinoma. Int J Cancer. 2019, 144:1313-1320. 10.1002/ijc.31971

9. Shah AA, Lamarre ED, Bishop JA: Human papillomavirus-related multiphenotypic sinonasal carcinoma: a case report documenting the potential for very late tumor recurrence. Head Neck Pathol. 2018, 12:623-628. 10.1007/s12105-018-0895-5

10. Youlden DR, Cramb SM, Peters S, Porceddu SV, Møller H, Fritschi L, Baade PD: International comparisons of the incidence and mortality of sinonasal cancer. Cancer Epidemiol. 2013, 37:770-779. 10.1016/j.canep.2013.09.014

11. Sanghvi S, Khan MN, Patel NR, Yeldandi S, Baredes S, Eloy JA: Epidemiology of sinonasal squamous cell carcinoma: a comprehensive analysis of 4994 patients. Laryngoscope. 2014, 124:76-83. 10.1002/lary.24264

12. Cantu G, Solero CL, Miceli R, et al.: Anterior craniofacial resection for malignant paranasal tumors: a monoinstitutional experience of 366 cases. Head Neck. 2012, 34:78-87. 10.1002/hed.21685

13. Lewis JS Jr: Sinonasal squamous cell carcinoma: a review with emphasis on emerging histologic subtypes and the role of human papillomavirus. Head Neck Pathol. 2016, 10:60-67. 10.1007/s12105-016-0692-y

14. Turner JH, Reh DD: Incidence and survival in patients with sinonasal cancer: a historical analysis of population-based data. Head Neck. 2012, 34:877-885. 10.1002/hed.21830

15. Becker C, Kayser G, Pfeiffer J: Squamous cell cancer of the nasal cavity: new insights and implications for diagnosis and treatment. Head Neck. 2016, 38:2112-2117. 10.1002/hed.24391

16. Eichhorn KW, Bootz F: Clinical requirements and possible applications of robot assisted endoscopy in skull base and sinus surgery. Acta Neurochir Suppl. 2011, 109:237-240. 10.1007/978-3-211-99651-5_37

17. Duprez F, Madani I, Morbée L, et al.: IMRT for sinonasal tumors minimizes severe late ocular toxicity and preserves disease control and survival. Int J Radiat Oncol Biol Phys. 2012, 83:252-259. 10.1016/j.ijrobp.2011.06.1977

18. Spiotto MT, Weichselbaum RR: Comparison of 3D confromal radiotherapy and intensity modulated radiotherapy with or without simultaneous integrated boost during concurrent chemoradiation for locally advanced head and neck cancers. PLoS One. 2014, 9:e94456. 10.1371/journal.pone.0094456

19. Alonso-Basanta M, Lustig RA, Kennedy DW: Proton beam therapy in skull base pathology . Otolaryngol Clin North Am. 2011, 44:1173-1183. 10.1016/j.otc.2011.08.012

20. Kies MS, Holsinger FC, Lee JJ, et al.: Induction chemotherapy and cetuximab for locally advanced squamous cell carcinoma of the head and neck: results from a phase II prospective trial. J Clin Oncol. 2010, 28:8-14. 10.1200/JCO.2009.23.0425 